\title{
Pandemic effect on the elderly and their caregivers
}

\author{
Maryelizabeth Tidiya Walarine ${ }^{1^{*}}$, Binoy Mathew $\mathrm{K} \mathrm{V}^{2}$
}

\begin{abstract}
COVID-19 pandemic forced governments to enact mobility restrictions to contain the spread of infection. Elderly, especially those with co-morbidities, are highly susceptible to infections. Hence, reverse quarantine measures have been enacted to protect the elderly. The barriers in social connectedness have an impact on the mental and physical well-being of the elderly. Stress, anxiety, anger, confusion, depression, and suicidal tendencies are reported among the elderly kept in social isolation. Apart from the elderly, their family caregivers also go through similar physical and psycho-social stress. Many times, the caregivers are also having additional responsibilities of childcare and homeschooling during the pandemic time. The authors outline the various intricate issues and dimensions of the pandemic's effect on the elderly and their caregivers. Various feasible strategies to address these multidimensional problems faced by the elderly and their caregivers during the pandemic time, like mobile-based mindfulness meditation training, spiritual support, telephone-based psychotherapy, telehealth services, physical exercise promotion, and social support measures, are recommended.
\end{abstract}

Keywords: Caregiver, Coping, COVID-19, Elderly, Pandemic, Prevention, Stress, India

\section{Background}

In the time of COVID-19, where coronavirus disease has spread Social connections put into an important role in maintaining well-being of the elderly [1]. Elderly and people with multiple systemic disorders like hypertension, heart disease, diabetes, asthma, etc., are at high risk of incurring COVID-19 [2]. Mobility constraints, which had been enacted as precautionary measures against the outbreak of the COVID-19 pandemic, had created barriers for social connectivity among the elderly. The social isolation thus created had been found to exponentially hiked anxiety levels and resultant behavioral problems among the elderly [1]. People kept in social isolation and quarantine experience loneliness, post-traumatic stress symptoms, confusion, anger, depression, and suicidal tendencies [3-6]. Fear of being a burden to the family added up with social isolation was the factor that led to suicide among older women in Hong Kong during the SARS pandemic [7].

Age-related changes like the decline in the rate of clearance of particles, reduced resistance in the nasal area, decrease in the number of ciliated cells and size of the upper respiratory tract, and malnutrition occur in the elderly. Supplemented to it, agerelated dysfunction of innate and adaptive immune system predisposes elderly to COVID-19 like viral infections

*Correspondence: haitidiya@gmail.com

${ }^{1}$ Department of Medical-Surgical Nursing, MIMS College of Nursing,

Malappuram, India

Full list of author information is available at the end of the article
[8].Furthermore; all these restrictions have a deleterious effect on the physical activity level of the elderly, making the situation more worsened. It has been reported that the elderly drastically loses muscle strength, aerobic capacity, and flexibility due to limitations, inactivity, and increase risk of fall [9-11].

The caregivers of the elderly are playing a significant role, but many times they are taken for granted. In developing countries like India, family members are the primary caregivers. Many a time, they experience the feeling of being entrapped in a situation due to their obligatory liabilities [12]. The caregivers often bear stress and frustration of the elderly expressed as anger and other emotional outbursts. An equal proportion of stress is likely to be experienced by them. Lack of definite treatment, the rapid spread of infection, uncertainty regarding the modes of transmission, length of quarantine, financial constraints, changes in personal care, and social routines were detected to be some of the critical factors predisposing caregivers to stress [13,14].Fake news, rumors, and myths related to COVID-19 having been rapidly spread through social media cause confusion and treatment dilemmas among the caregivers and are likely to affect their mental health [15].Stress is found to increase steroids' production in the body, impairing the immune system and making people susceptible to infections [16].There are alterations in cytokines, white blood cells, and peripheral $\mathrm{C}$ Reactive protein in persons with depression or anxiety [17-19].Unfortunately, caregivers often fail to recognize these stress-related physical effects and develop long-lasting physical and mental illnesses [12]. 
In the elderly with COVID-19 infection, medical co-morbidities like diabetes and hypertension increase the risk of mortality [1]. Certain veterans with malignant cancer, heart failure, stroke, require advanced and complex caregiving procedures. In such situations, COVID 19 infection superadds caregiver burden [20]. Some family members are having additional responsibilities of childcare and homeschooling apart from caring elderly [20]. Social interaction limitations cause children to become restless, annoyed, and agitated, resulting in enhancing psychological burden to the parents [21].During the initial phase of the pandemic in China, a survey reported that $75 \%$ of the people were worried about the family members getting COVID-19 [22]. Some of the caregivers of the elderly are up to the age of their care recipients, with various neurological and musculoskeletal conditions making the situation complex. The number of aged parents staying alone is a common phenomenon due to the change in family structure.

Home care of COVID-19 is considered when the symptoms are mild, and hospital stay is unsafe, especially for the elderly [23]. Caregivers of the elderly are reluctant to seek external help due to social isolation restrictions, and fear of infection transmission through visitors, increasing their mental stress and physical exhaustion [20]. Increased caregiver stress and burnouts are already recognized as an important public health issue [20]. Depression and suicidal thoughts are also experienced by caregivers [24]. The relatives of a terminally ill patient with COVID-19 are found to be anxious, afraid, and alone. Most of the caregivers have not undergone any caregiver specific training. Hence, providing adequate telephone-based clinical caregiving guidance, emotional and psychological supports are of great relevance [25].

Unemployment and income reduction are experienced by caregivers during the COVID-19, causing an economic crisis [20]. Besides, many of the employees are reluctant to disclose their additional responsibility as a caregiver, owing to the fear of losing a job [26]. The stigma associated with the pandemic causes people to avoid seeking medical care even if they have symptoms [27]. Medical professionals, nurses, and caregivers form the main pillars of the healthcare delivery system. Hence measures to mitigate the stress and effective coping strategies for both the elderly and their caregivers are of paramount importance for their physical and emotional well-being and enhancing their quality of life.

\section{Recommendations}

Mental tension, stress, and associated factors had been found to influence the elderly and their caregivers to a great extent. Inducing peace of mind can mitigate a wide range of issues faced by these vulnerable populations. Meditation helps address loneliness among the elderly [28]. Mobile-based mindfulness meditation training was found effective in addressing loneliness and stress in the elderly [29]. Caregivers can be trained to promote their care recipients in performing self-meditation.

The elderly will be more into spiritual commitments, find more mental comfort from spiritual elements like services, prayers, religious speeches, hearing recitation of holy scriptures, etc. Spiritual support is of great help to patients and relatives during the end stage of life and acts as "spiritual first aid" [25].

Psychotherapy offers a realistic view of one's mental situation and methods to tackle the crisis with clinician-guided training. In situations like COVID-19, telephone-based psychotherapy has proved to provide high satisfaction and retention rate [30].

Telehealth is an effective solution to access health care services. However, digital literacy and broadband access, especially among the elderly and those residing in rural areas, are the main barriers [20]. Otherwise, it was an ideal option during reverse quarantine of the elderly in pandemic time. However, making caregivers empowered by providing necessary skill training and guidance facilitates better healthcare services utilization. On the other hand, a continuous telecommunication link could also be established with a nurse or doctor to monitor and provide feedback [23].

Teaching coping strategies to the caregivers can alleviate major issues of the elderly. Active coping, distraction, and seeking emotional and social support were the most effective coping strategies [14].Patients and family members should be provided educational support regarding basic precautionary and hygiene measures to prevent the spread of infection and for symptom management [23].

Cognitive deterioration is one of the physiological changes occurring with senescence. The elderly with cognitive issues should be provided special care as they are likely to get more stressed, agitated, or withdrawn [31]. Caregivers should be made aware of the same, and they must be prepared for facing cognition related issues from their side. Caregivers should minimize sharing spaces and maintain adequate ventilation in shared spaces.

When an elderly is suspected or confirmed having COVID19 infection, avoid caregiving responsibility to immunecompromised persons or persons with chronic conditions [23]. Proper disposal methods of infected waste materials of home quarantined elderly should be diligently followed and taught to the caregivers, devoid of which they would be exposing themselves and the significant others to a deadly virulent virus. Physical exercise bouts of 10-minute duration, done three times daily, will help the elderly achieve the recommended level of physical activity and counter age-associated immune deficiency [32,33]. Allowing caregivers of the elderly to be in employment increase their financial security, satisfaction, and social integration [34]. Provide simple and clear information to the elderly and their caregivers about COVD-19 infection and preventive measures. Maintain adequate stock of regular medicines being taken for systemic diseases by the elderly. A social network needs to be created to supply medicine and essential goods to the elderly and caregivers. Providing incentives to caregivers of the elderly will be an ideal strategy as it helps relieve the financial burden, acts as a motivator, and a sign of recognition of their services.

Abbreviation

COVID-19: Coronavirus Disease-19; MIMS: Malabar Institute of Medical Sciences

\section{Delectation \\ Acknowledgment \\ None}

\section{Funding}

The authors received no financial support for their research, authorship, and/or publication of this article. 
Availability of data and materials

Data will be available by emailing haitidiya@gmail.com

\section{Authors' contributions}

Authors were equally involved in all parts of the manuscript (Viewpoint) drafting, concept, design, writing, reviewing, editing, and approving the manuscript in its final form. Authors have read and approved the final manuscript.

\section{Ethics approval and consent to participate}

We conducted the research following the Declaration of Helsinki. However, Viewpoint Articles need no ethics committee approval.

\section{Consent for publication}

Not applicable

\section{Competing interest}

The author declares that he has no competing interests.

\section{Open Access}

This article is distributed under the terms of the Creative Commons Attribution 4.0 International License (http://creativecommons.org/licenses/by/4.0/), which permits unrestricted use, distribution, and reproduction in any medium, provided you give appropriate credit to the original author(s) and the source, provide a link to the Creative Commons license, and indicate if changes were made. The Creative Commons Public Domain Dedication waiver (http://creativecommons.org/publicdomain/zero/1.0/) applies to the data made available in this article, unless otherwise stated.

\section{Author details}

${ }^{1}$ Department of Medical-Surgical Nursing, MIMS College of Nursing, Malappuram, India. ${ }^{2}$ Department of Physiotherapy, Composite Regional Centre for Persons with DisabilitiesKozhikode, India.

Article Info

Received: 27 September 2020

Accepted: 31 October 2020

Published: 24 November 2020

\section{References}

1. Van Orden KA, Bower E, Lutz J, Silva C, Gallegos AM, Podgorski CA, et al. Strategies to Promote Social Connections Among Older Adults During "Social Distancing” Restrictions. Am J Geriatr Psychiatry [Internet]. 2020 May 18. https://doi.org/10.1016/j.jagp.2020.05.004

2. Mahajan P, Kaushal J. Epidemic Trend of COVID-19 Transmission in India During Lockdown-1 Phase. J Community Health. 2020 Dec;45(6):1291-1300. https://doi.org/10.1007/s10900-020-00863-3

3. Brooks SK, Webster RK, Smith LE, Woodland L, Wessely S, Greenberg N, et al. The psychological impact of quarantine and how to reduce it: rapid review of the evidence. Lancet [Internet]. $2020 \quad$ Mar 14;395(10227):912-20. https://doi.org/10.1016/S0140-6736(20)30460-8

4. Robertson E, Hershenfield K, Grace SL, Stewart DE. The Psychosocial Effects of Being Quarantined following Exposure to SARS: A Qualitative Study of Toronto Health Care Workers. Can J Psychiatry [Internet]. 2004 Jun 29;49(6):403-7. https://doi.org/10.1177/070674370404900612

5. Jeong H, Yim HW, Song Y-J, Ki M, Min J-A, Cho J, et al. Mental health status of people isolated due to Middle East
Respiratory Syndrome. Epidemiol Health [Internet]. 2016 Nov 5;38: e2016048. https://doi.org/10.4178/epih.e2016048

6. Liu X, Kakade M, Fuller CJ, Fan B, Fang Y, Kong J, et al. Depression after exposure to stressful events: lessons learned from the severe acute respiratory syndrome epidemic. Compr Psychiatry [Internet]. 2012 Jan;53(1):15-23. https://doi.org/10.1016/j.comppsych.2011.02.003

7. Yip PSF, Cheung YT, Chau PH, Law YW. The impact of epidemic outbreak: the case of severe acute respiratory syndrome (SARS) and suicide among older adults in Hong Kong. Crisis [Internet]. 2010 Mar;31(2):86-92. https://doi.org/10.1027/0227-5910/a000015

8. Perrotta F, Corbi G, Mazzeo G, Boccia M, Aronne L, D'Agnano V, et al. COVID-19 and the elderly: insights into pathogenesis and clinical decision-making. Aging Clin Exp Res [Internet]. $2020 \quad$ Aug 16;32(8):1599-608. https://doi.org/10.1007/s40520-020-01631-y

9. Avlund K, Vass M, Hendriksen C. Onset of mobility disability among community-dwelling old men and women. The role of tiredness in daily activities. Age Ageing [Internet]. 2003 Nov

$1 ; 32(6): 579-84$

https://doi.org/10.1093/ageing/afg101

10. Coker RH, Hays NP, Williams RH, Wolfe RR, Evans WJ. Bed Rest Promotes Reductions in Walking Speed, Functional Parameters, and Aerobic Fitness in Older, Healthy Adults. Journals Gerontol Ser A Biol Sci Med Sci [Internet]. 2015 Jan 1;70(1):91-6. https://doi.org/10.1093/gerona/glu123

11. Storeng SH, Sund ER, Krokstad S. Factors associated with basic and instrumental activities of daily living in elderly participants of a population-based survey: the Nord-Trøndelag Health Study, Norway. BMJ Open [Internet]. 2018 Mar 12;8(3): e018942. http://dx.doi.org/10.1136/bmjopen-2017-018942

12. Kulkarni P, Kulkarni P, Ghooi R, Bhatwadekar M, Thatte N, Anavkar V. Stress among care givers: The impact of nursing a relative with cancer. Indian $\mathbf{J}$ Palliat Care [Internet]. 2014;20(1):31. https://doi.org/10.4103/0973-1075.125554

13. Spoorthy MS, Pratapa SK, Mahant S. Mental health problems faced by healthcare workers due to the COVID-19 pandemic-A review. Asian J Psychiatr [Internet]. 2020 Jun; 51:102119. https://doi.org/10.1016/j.ajp.2020.102119

14. Park CL, Russell BS, Fendrich M, Finkelstein-Fox L, Hutchison M, Becker J. Americans' COVID-19 Stress, Coping, and Adherence to CDC Guidelines. J Gen Intern Med [Internet]. 2020 May 29; Available from: https://doi.org/10.1007/s11606020-05898-9

15. Banerjee D. The COVID-19 outbreak: Crucial role the psychiatrists can play. Asian J Psychiatr [Internet]. 2020 Apr; 50:102014. https://doi.org/10.1016/j.ajp.2020.102014

16. Dinakaran D, Manjunatha N, Naveen Kumar C, Suresh BM. Neuropsychiatric aspects of COVID-19 pandemic: A selective review. Asian J Psychiatr [Internet]. 2020 Oct 30; 53:102188. https://doi.org/10.1016/j.ajp.2020.102188

17. Valkanova V, Ebmeier KP, Allan CL. CRP, IL-6 and depression: A systematic review and meta-analysis of longitudinal studies. J Affect Disord [Internet]. 2013 Sep 25;150(3):736-44. https://doi.org/10.1016/j.jad.2013.06.004 18. Shafiee M, Tayefi M, Hassanian SM, Ghaneifar Z, Parizadeh MR, Avan A, et al. Depression and anxiety symptoms are associated with white blood cell count and red cell distribution width: A sex-stratified analysis in a populationbased study. Psychoneuroendocrinology [Internet]. 2017 Oct; 84:101-8. https://doi.org/10.1016/j.psyneuen.2017.06.021 19. Köhler CA, Freitas TH, Maes M, de Andrade NQ, Liu CS, Fernandes BS, et al. Peripheral cytokine and chemokine alterations in depression: a meta-analysis of 82 studies. Acta Psychiatr Scand [Internet]. 2017 May;135(5):373-87. https://doi.org/10.1111/acps.12698

20. Kent EE, Ornstein KA, Dionne-Odom JN. The Family Caregiving Crisis Meets an Actual Pandemic. J Pain Symptom Manage [Internet]. $2020 \quad$ Jul;60(1): e66-9. https://doi.org/10.1016/j.jpainsymman.2020.04.006 
21. Wang G, Zhang Y, Zhao J, Zhang J, Jiang F. Mitigate the effects of home confinement on children during the COVID-19 outbreak. Lancet [Internet]. 2020 Mar 21;395(10228):945-7. https://doi.org/10.1016/S0140-6736(20)30547-X

22. Wang C, Pan R, Wan X, Tan Y, Xu L, Ho CS, et al. Immediate Psychological Responses and Associated Factors during the Initial Stage of the 2019 Coronavirus Disease (COVID-19) Epidemic among the General Population in China. Int J Environ Res Public Health [Internet]. 2020 Mar 6;17(5):1729. https://doi.org/10.3390/ijerph17051729

23. Tonin L, Lacerda MR, Caceres NT de G, Hermann AP. Recommendations in covid-19 times: a view for home care. Rev Bras Enferm [Internet]. 2020;73Suppl 2(Suppl 2): e20200310. https://doi.org/10.1590/0034-7167-2020-0310

24. Kumar V, Singh A, Tewari M, Kaur S. Caregivers' perspective on home-based care of operated neurosurgery patients discharged from PGIMER, Chandigarh, India. Indian J
Palliat Care
[Internet].
2015;21(2):253.

https://doi.org/10.4103/0973-1075.156513

25. Selman LE, Chao D, Sowden R, Marshall S, Chamberlain C, Koffman J. Bereavement Support on the Frontline of COVID-19: Recommendations for Hospital Clinicians. J Pain Symptom Manage [Internet]. 2020 May 4. https://doi.org/10.1016/j.jpainsymman.2020.04.024

26. Tehan M, Thompson N. Loss and Grief in the Workplace: The Challenge of Leadership. OMEGA - J Death Dying [Internet]. 2013 May;66(3):265-80. https://doi.org/10.2190/OM.66.3.d

27. Dubey S, Biswas P, Ghosh R, Chatterjee S, Dubey MJ, Chatterjee S, et al. Psychosocial impact of COVID-19. Diabetes Metab Syndr [Internet]. 2020 May 27;14(5):779-88. https://doi.org/10.1016/j.dsx.2020.05.035

28. Creswell JD, Irwin MR, Burklund LJ, Lieberman MD, Arevalo JMG, Ma J, et al. Mindfulness-Based Stress Reduction training reduces loneliness and pro-inflammatory gene expression in older adults: a small randomized controlled trial. Brain Behav Immun [Internet]. 2012 Oct;26(7):1095-101. https://doi.org/10.1016/j.bbi.2012.07.006

29. Lindsay EK, Young S, Brown KW, Smyth JM, Creswell JD. Mindfulness training reduces loneliness and increases social contact in a randomized controlled trial. Proc Natl Acad Sci [Internet]. $\quad 2019 \quad$ Feb $26 ; 116(9)$ :3488-93. https://doi.org/10.1073/pnas.1813588116

30. Brenes GA, Ingram CW, Danhauer SC. Benefits and challenges of conducting psychotherapy by telephone. Prof Psychol Res Pract [Internet]. 2011 Dec;42(6):543-9. https://doi.org/10.1037/a0026135

31. Castro-de-Araujo LFS, Machado DB. Impact of COVID-19 on mental health in a Low and Middle-Income Country. Cien Saude Colet [Internet]. 2020 Jun;25(suppl 1):2457-60. https://doi.org/10.1590/1413-81232020256.1.10932020

32. World Health Organization (WHO). Global Strategy on Diet, Physical Activity and Health: Physical Activity and Older Adults -Recommended levels of physical activity for adults aged 65 and above [Internet]. 2020 [cited 2020 Jul 12]. Available from: https://www.who.int/dietphysicalactivity/factsheet_olderadults/ en/

33. Nieman DC. Exercise Immunology: Future Directions for Research Relatedto Athletes, Nutrition, and the Elderly. Int J Sports Med [Internet]. 2000 May;21(Supplement 1):61-8. https://doi.org/10.1055/s-2000-1453

34. Phillips D, Paul G, Fahy M, Dowling-Hetherington L, Kroll $\mathrm{T}$, Moloney B, et al. The invisible workforce during the COVID-19 pandemic: family carers at the frontline. HRB Open $\begin{array}{lllll}\text { Res } & \text { [Internet]. } & 2020 \quad \text { May } & \end{array}$ https://doi.org/10.12688/hrbopenres.13059.1 